\title{
AN INDIVIDUALISED LITERACY INTERVENTION FOR LOW PROGRESS READERS AND WRITERS IN THE FOUNDATION PHASE
}

\author{
M Swart \& R Nathanson ${ }^{1}$ \\ Stellenbosch University
}

Current literacy interventions (i.e. programmes of instruction for low-progress readers and writers that are supplementary to the literacy programmes used in mainstream classrooms) implemented in most Western Cape schools reflect the use of isolated item-based literacy teaching methods. The low literacy levels in the Western Cape primary grades, however, do not indicate successful literacy learning. This article describes an individualised literacy intervention for emergent literacy learners that explored alternative, research-based methods of instruction. The intervention took shape as a comparison between low-progress learners who participated in the literacy intervention and average-progress learners who did not participate in this intervention. The aim was to accelerate the low-progress learners' literacy learning so that they could reach the average-band performance of their classmates after 12 weeks in the intervention. Qualitative and quantitative data were gathered by means of observations of learners and assessment results obtained in a pre-test-post-test design, with the addition of a mid-test to observe learners' literacy progress. Based on qualitative data, the intervention proved to be successful, because observations indicated positive change in the low-progress learners' reading and writing behaviours. Given the small sample size, the overall trend in the quantitative data supported the value of the intervention and indicated a need for extending the research beyond a pilot study. Further research using larger sample sizes is thus recommended.

\section{Keywords}

Early literacy intervention, reading strategies, comprehension instruction, reading and writing problems

\section{INTRODUCTION}

In a world of ever-progressing information and technology, literacy plays a vital part in the process of learning how to learn (Boekhorst \& Britz, 2004; Hornsby, 2000). The ability to read therefore is each individual's key to independent learning and to unlocking the world of knowledge, whether this means reading a label or reading a book on electronics (Hornsby, 2000: 2). The sooner children learn to read, the sooner they can access knowledge and increase their learning. However, if children do not learn to read by the end of the foundation phase, their chances of attaining advanced levels of learning are severely jeopardised (

\footnotetext{
${ }^{1}$ This article is based on Swart's dissertation supervised by R. Nathanson and presented for the Degree of Master of Education at Stellenbosch University.
} 
Gersten \& Dimino, 2006; Pinnell \& Fountas, 2009). Thus, the first stages of learning to read lay the foundation for success in a competitive, information-driven world.

Given that the first stages of entering the literate world are so important, primary school learners should be able to experience success in their reading and writing attempts. This sentiment is expressed in the 'every child can read' campaign that was launched in South Africa by the Department of Education in 2002. Unfortunately, this is not the case. National and international assessments of the literacy levels in South African schools reveal that approximately $70 \%$ of primary school children are not able to read at grade level in their schools' language of learning and teaching (LoLT) (Fleisch, 2008; International Association for the Evaluation of Educational Achievement, 2008; Grant, 2009). Arguably, there are many possible reasons for these dismal results, such as schools being poorly resourced while serving large classes of children from low-socio economic backgrounds, which make it difficult for classroom teachers to address the needs of individual children. However, these arguments could conceal the important role instructional methods play in learning to read and write. Numerous studies have pointed out that instruction in many local mainstream and special needs classrooms is not in line with research-based practices (Flanagan, 1995; Bloch, 2006; Nathanson, 2008; Swart, 2011).

Although the lowest national test results in literacy were obtained from schools serving lowsocio-economic communities (WCED, 2005; Fleisch, 2008), it is possible that high literacy rates in affluent schools may in large measure be attributed to the literate backgrounds of the learners who attend these schools, rather than just excellent teaching. This, also, could mask the fact that instruction in top achieving schools is not meeting the needs of children who are struggling to read and write. As Clay (2001: 238) points out, group averages can lead to large prediction errors for individuals and they do not allow planners or teachers to make sound policy or instructional decisions for individual children. These contentions prompted me to ask (a) Could a different instructional approach enable low-progress readers to perform at average levels for their class? (b) Can the lowest achievers learn effective reading strategies that will enable them to process text successfully? (c) What would the wider implications of the findings to these research questions be for literacy educators and researchers?

To explore these questions, I implemented a one-to-one early literacy intervention in a middle to high income school where I worked as a tutor for low-progress readers and writers. As Clay (1991) and Justice (2006) suggest and my own teaching experiences confirm, the reading process can 'go wrong' in the first year of school. Therefore, I adopted a three-tiered approach which focused on prevention rather than cure, namely: (1) the early identification of learners in need of intervention before ineffective reading behaviours become habituated and the weight of failure makes success more difficult; (2) a socio-cognitive approach to teaching literacy which was different to the traditional approach used in mainstream and special needs classrooms; and (3) a brief intervention period aimed at accelerating the progress of 'slow learners' in an individualised teaching situation.

Based on the results of this pilot study, the aim of this article is to discuss the contribution that the study can make to literacy instruction and research. The remainder of the article commences with a discussion of how the literature review shaped the intervention implemented in the pilot study. This is followed by an outline of the research methodology and a report of the research findings. The article concludes with some recommendations and closing remarks. 


\section{LITERATURE REVIEW}

Given that prevention and acceleration were essential concepts in my approach to intervention, the literature review focuses on theorists whose research is relevant to elucidating these concepts and whose work most influenced my thinking (Clay, 1991; Fountas \& Pinnell, 2007; Calkins, 2001; McEneany, Lose \& Schwartz, 2006). Much of the pioneering research in early intervention can be traced back to Clay's (1975) early work with low-progress children and to her determination to find better ways of helping them (Calkins, 2001; Pinnell \& Fountas, 2006). Although Clay's work is widely recognised and has become a strong foundation for other researchers, many of her views conflict with traditional approaches to early reading instruction (Pinnell, Fried \& Estice, 1991; DeFord, 1991; McCarrier, 2001; Lyons, 2003; Fountas \& Pinnell, 2007). In contrast with theorists who simplify the reading acquisition process by focusing on single variables, such as letter recognition, word identification and phonological awareness, Clay (2001: 236) contends that a 'complex theory in the developmental perspective' provides the most accelerative and preventive thrust in early interventions. She argues that formal literacy instruction should capitalise on the complex cognitive systems preschool children have constructed informally through learning to speak and making sense of the world. With each interaction with the physical and social world, young learners improve and expand these 'self-extending' systems. Similarly, out of early reading and writing experiences, young learners create a network of cognitive competencies, which 'power subsequent independent literacy learning' (Clay, 1991: 325).

It is therefore critical that literacy activities should be designed to enlist the language competencies children already have, rather than put them on hold till they have mastered a contrived set of simplified tasks (Cazden \& Clay, 1992: 118; Clay, 2001: 94). It is equally important for beginner readers to attend to the messages in continuous texts (i.e. groups of words at sentence and discourse levels) and not just to practise isolated items, such as sounds, letters and words (Clay, 2001; Fountas \& Pinnell, 2007). When reading continuous texts, children learn to make use of cues such as drawing on prior knowledge to gain meaning, using syntax and searching for visual information in print. These strategic behaviours are influenced by knowledge of the domain, prior achievement, motivation and cognitive individual differences (Dermitzaki, Andreou \& Paraskeva, 2008: 472).

Clay's (2005) insistence on teaching low-progress readers how to use strategies for gaining meaning from continuous texts, derives from her focus on reading proficiency, rather than on deficiency. Instead of questioning what causes reading difficulties, her research examined how successful readers process text (Pinnell \& Fountas, 2006: 364). She then used that knowledge to help struggling readers become proficient readers (Pinnell \& Fountas, 2006: 364). She argued that several kinds of perceptual and cognitive systems are 'critical for extending literacy processing power' and that young readers have to 'orchestrate' complex cognitive operations early in the reading process (Clay, 2001: 91). Rejecting the common assumption that reading is simply a matter of recognising words, she argues that reading and writing are concurrent sources of learning about the complexities of print that can significantly accelerate progress in literacy learning (Clay, 2001 :92).

It is the strategic processes of learning how to use sources of information in texts and how to link these to prior knowledge that makes reading successful. An important conclusion to draw from these arguments is that strategic processes cannot be learned from studying 
subcomponent parts in isolation. One needs 'a context for a subcomponent in order to derive rules about its probabilities of occurrence' (Clay, 1991: 333). Whereas proficient readers and writers build complex reading and writing processes from the beginning, poor readers often fail to do so (Fountas \& Pinnell, 2007, Clay, 2002). They do not search for information in texts effectively and they have not learned the complex relationship between knowing items of knowledge and using items strategically to make meaning of continuous texts (Clay, 1991: 320).

From these arguments is evident that Clay's work is based on a generic theory, namely learning which generates further learning as children draw on their prior knowledge and on cues in continuous text to construct meaning. Her focus is on the development of intentional, self-managed learning strategies for meaning construction, rather than on routinised performances. Two powerful principles that can be derived from Clay's work are (a) that the development of a generative system is more important than the production of a correct product (Clay, 2001) and (b) that educators should 'recognize the complexity of the reading process from the beginning', which implies a need for instruction that helps individual children develop complex neural systems early in the learning-to-read process (Pinnell \& Fountas, 2006: 34).

By studying the complexity of the human mind, neuroscientists have gained valuable insights into how the brain 'grows, develops and functions', which provide a neurological foundation for reading instruction (Lyons, 2003: 7). These insights also challenge a number of conventional assumptions. Contrary to the assumptions that brain structures are wholly determined by genetics and that they are permanently established during childhood, neuroscience indicates that the growth and development of the brain depend heavily on environmental input and the quality of the experiences children have (Dryden \& Vos, 1994; Lyons, 2001, 2003; Caine, 2008). Lyons (2003: 23) points out that children living in lowsocio-economic communities develop different brain structures to children living in enriched environments. Lyons, however, states that subsequent exposure to enriched environments can induce positive anatomic changes in such children's brains. Neural networks can be reorganised and regrown through experience (Gopnik, Meltzoff \& Kuhl, 1999).

Neurons that form maps in the brain do not consist of bits and pieces of isolated information; they construct a network in an individual way for every person, which is uniquely linked according to each person's own experience (Lyons, 2003: 16). The first implication of this is that successful reading and writing depend on networks of neurons working in parallel and integrated ways to extract meaning from sources of information in written texts (Rumelhart \& McClelland, 1986; Lyons, 2003). A second implication for literacy educators is that one of the most effective ways to create these intricate links in the brain is to build on a learner's own sources of knowledge and strengths (DeFord, Lyons \& Pinnell, 1991: 6; Martin \& Hydén, 2006). Given the unique structure of each individual's brain, the third implication is that each child will have different cognitive and emotional responses to learning (Caine, 2008; Pinnell \& Fountas, 2006).

Lyons (2003) draws attention to the emotional and social dimensions of learning to read. She states that children with low reading skills 'experience loss of self-esteem, confidence and initiative and have emotional traumas that may last for a lifetime' (Lyons, 2003: 1). In a similar vein, Dahl and Freppon (1998: 272) emphasise the personal and social nature of the learning process. They criticise item-based reading programmes on the grounds that these 
programmes cause many children to disengage from the literacy process. Goleman (1995), O'Neil (1996) and Dodge (2009) state that Emotional Intelligence (EI) is more important than Intelligence Quotient (IQ) yet this aspect of learning is largely ignored by policy makers, who strongly advocate accountability and test scores as mechanisms for improving literacy levels. Because individual diversity is either 'averaged out' in test scores or largely ignored by a 'one programme fits all' approach to beginner reading instruction, there is a need for alternative ways of describing and assessing progress, which can help educators solve individual children's literacy problems (Block \& Parris, 2008; Clay, 2001: 4; Lyons, 2003).

Vygotsky's (1978) socio-cultural theory of learning takes into account children's developing emotional and cognitive abilities. Vygotsky argued that the purpose of instruction is to provide children with experience in their zones of proximal development (ZPD). Dorn, French and Jones (1998: 4) describe the child's ZPD as 'the distance between the actual level of development and the potential level of development'. This is the zone within which the expert teacher 'scaffolds' each child's learning process until the child can function independently. This implies that children's development depends heavily on teachers' abilities to create opportunities for learning and not merely on the children's inherent potential. It follows that some styles of teaching might nurture emotional and cognitive development and some styles might limit opportunities to learning. Similarly, some kinds of reading activities and texts can foster strategic learning that helps children become independent learners, while other kinds of literacy activities might impede such learning (Clay, 1991; DeFord et al., 1991). One implication of this is that instruction which directs attention to letters, sounds or single words, may prevent some children from developing important reading strategies for dealing with continuous text. Thus, education contributes to reading failure if it limits children's reading experiences to text that prevent them from developing reading strategies for understanding messages in text (Clay, 1991: 2002).

Based on the literature review outlined above, I advocate a model of reading acquisition which defines reading as 'working on continuous text' with meaning as the 'focal point' of attention (Clay, 2001: 340). It promotes flexible meaning construction in a variety of texts and genres (Flanagan, 1995; Hornsby, 2000). I developed the view that the most accelerative and preventative framework for the literacy intervention in my pilot study would nurture children's 'sense of self as readers and writers' by requiring them to engage in reading and writing continuous texts with my help from the first day of the intervention. In addition, two of Vygotsky's key ideas, namely that expert teaching leads cognitive and social development and that children's learning should progress from adult assistance to self-assistance were foundational to the intervention I planned. Based on these views, I formulated the following guiding principles for the intervention:

- engaging children in meaningful reading and writing from the first day of the intervention

- valuing the reciprocity of reading and writing

- acknowledging the complexity of the reading process from day one and hence teaching strategies for understanding how to use letter, sound and word knowledge to communicate meaning and solve novel features in print

- providing early, individualised instruction in each child's zone of proximal development

- ensuring quality of teacher-learner interaction about texts (through discussion, instructional dialogue and prompting) 
- focusing on building independent learners (e.g. by prompting learners to initiate strategic actions, such as using prior knowledge, predicting, monitoring their reading, rereading, self-correcting and using cues in text)

\section{RESEARCH AIM, QUESTIONS AND DESIGN}

The research aim was to obtain data indicating whether a one-to-one research-based intervention could help struggling readers and writers progress to the average or near-average range of performance of their classmates. The intervention was based on the assumption that individual tuition based on learner needs and delivered daily for thirty minutes would help children develop effective strategies for comprehending texts (Clay, 1991; Pinnell \& Fountas, 2006). The research findings could be used to inform literacy instruction and future research.

The research design can be categorised as a multi-method design, which included qualitative and quantitative data (Purcell-Gates, 2006). To investigate the quantitative data, I used a quasi-experimental pre-test/post-test design with the addition of a mid-test to observe the learners' literacy progress (Singleton, Straits \& Straits, 1993: 230; Leedy, 1993: 302; PurcellGates, 2006: 2). I wanted to investigate the effectiveness of an individualised programme by comparing learners who had received additional literacy support to those who had not (Mujis \& Reynold, 2003; McEneany, Lose \& Schwartz, 2006).. The learners who received the added literacy support were 'low' achievers and the learners in the control group were 'average' achievers in literacy, according to their class teacher's assessments and observations. The decision to use average learners in the control group was based partly on the view that 'individually designed and individually delivered lessons can bring the child's progress back into the average band of achievement in a very short time' (Clay, 1993: 1). Therefore, the design had to include the variable towards which the individualised programme strives, namely the literacy level of an average learner in the same class as the literacy research programme participant..

\section{RESEARCH SAMPLE AND INTERVENTION}

As mentioned earlier, I implemented a one-to-one literacy intervention in a middle- to highincome school in the Helderberg basin where I worked as a learning support tutor for lowprogress readers and writers. The LoLT of instruction in the school was English. I employed a purposive sampling technique to select eight English-speaking learners from four Grade 1 classrooms (one low-progress and one average-progress learner from each classroom) to participate in the intervention. The mean age of the learners at initial testing was 6 years. For research purposes, the eight learners were divided into a control group and a target group. The control group consisted of four average-progress boys. The target group consisted of four low-progress learners. There were two boys and two girls in this group. In addition to their mainstream classroom lessons, the target group participated in the research-based literacy intervention that I designed.

The intervention started in mid-March 2010 and finished in June 2010. Every day, for a period of twelve weeks, I worked individually with the four learners in the target group. Instruction was based on the principles outlined in my literature review; on the feedback I obtained from systematic observations I had conducted (see data collection); and on my 
knowledge of each child's ZPD, which meant that lessons were moulded according to each child's competencies.

\section{DATA COLLECTION}

During the research, tests were conducted at three different times, namely the pre-test (March), mid-test (April) and post-test (June). During each test, every learner (in both the target and control groups) completed six assessments for analysis, which provided both qualitative and quantitative data. Each assessment was marked according to the guidelines set in Clay's (2002) An Observation Survey of Early Literacy Achievement.

The Observation Survey battery consists of six assessments, namely (1) Letter Identification, which tests a child's ability to identify letters of the alphabet by name or sound or as the first letter of a word; (2) Word test, which tests a child's ability to read a list of frequently used words; (3) Writing vocabulary, testing the ability to write words independently; (4) Hearing and Recording Sounds in Words, which tests ability to hear phonemes in words and to represent them by letters; (5) Concepts about Print for assessing what the child knows about print, for instance book handling skills, where to start reading and word-by-word matching in reading; (6) Running Record (an assessment of text reading) which provides evidence of how well children are using their knowledge of letters, sounds and words to understand messages in continuous texts.

During the data collection period, I fulfilled a dual role as researcher and teacher. As researcher I administered and analysed the Observations Survey tests according to the standard procedures set out in Clay's An Observation Survey of Early Literacy (2002) guidebook. As teacher I designed lessons based on the analysis of each learner's data. To obtain independent assessments of learner achievements, both the data collection and analyses were conducted in consultation with Duncan (2010) and Nathanson (2010).

\section{DATA MANAGEMENT, ANALYSIS AND PRESENTATION}

In addition to an interpretative discussion of the data obtained from the Observation Survey tests battery, a statistical analysis was performed on the data by the University of Stellenbosch's Centre for Statistical Consultation (Kidd, 2010) and represented in ANOVA tables, Fisher LSD tests and figures. It should be noted upfront that statistical analyses are usually based on bigger sample sizes, therefore all assessments in the intervention were expected to test non-significant (Kidd, 2010). If one therefore wanted to state that the intervention was successful on the basis of the statistical results, the small sample size would reduce the chance of making such a statement (Kidd, 2010), as small samples, having low power, could result in incorrect acceptance of the null hypothesis (i.e. a type II error). The statistical analysis in this pilot study was therefore conducted primarily to indicate whether there was a trend toward significance and to show whether follow-up studies with sufficient power would be feasible (Kidd, 2010).

Keeping the above-mentioned arguments in mind, the quantitative data were processed as follows: The raw scores from each learner's pre-, mid- and post-tests were calculated into averages and then processed and represented in figures. Mixed-model repeated measures ANOVA'S were conducted at the Stellenbosch University's Centre of Statistical Consultation 
(Kidd, 2010) with children (nested within groups) taken as random effect, time and group as fixed effects. Thus three fixed effects with the following hypotheses were tested:

- Time null hypothesis: averages for all the time points are equal, regardless of group;

- Group null hypothesis: averages of the two groups are equal, regardless of time;

- Time*Group interaction null hypothesis: differences between groups (if any) are equal for all time points.

A 5\% significance level $(\mathrm{p}<0.05)$ was used as guideline for significant effects (rejecting the null hypothesis). In the case of significant (or near significant) effects, Fisher least significant (LSD) post-hoc tests were conducted. The figures and discussions either proved or refuted an increase in the target group's average compared to that of the control group. Thus the figures showed whether the intervention was successful or not in raising the target group's average to that of the comparison group.

Given that non-significant results are typical of what one would expect from pilot studies with small numbers, the findings from the qualitative data were of considerable importance in deciding whether the intervention succeeded or not. In keeping with the interpretive character (Leedy, 1993: 141; Maykut \& Morehouse, 1994: 127; Paul \& Marfo, 2001: 532) of a qualitative study, my analysis of the qualitative data included descriptions of literacy processing behaviours (e.g. prediction, monitoring, repetitions, self-corrections and use of cues in texts); increases in language knowledge; and changes in children's personal interests in and attitudes toward reading.

The next section first provides an interpretative discussion of the quantitative data, then presents and discusses the statistical results and concludes with an interpretation of the qualitative data.

\section{RESULTS: INTERPRETATION OF QUANTITATIVE DATA}

As mentioned, there were two groups in my research, namely the control group and the target group. The learners in the control group were Dan, John, Rudolph and Bart; and the learners in the target group were Mia, Marc, Peter and Suzy (all names are pseudonyms). The percentages of each learner's pre-, mid- and post-test assessments were calculated and inserted into a spreadsheet on Excel. From there I used the 'average' function to calculate each learner's averages for all six assessments at each assessment time. These averages were then inserted into figure form, and are given in Figure 1. The y-axis represents the average percentages achieved and the $\mathrm{x}$-axis indicates the time at which each average was achieved, either at pre-, mid- or post-test. 


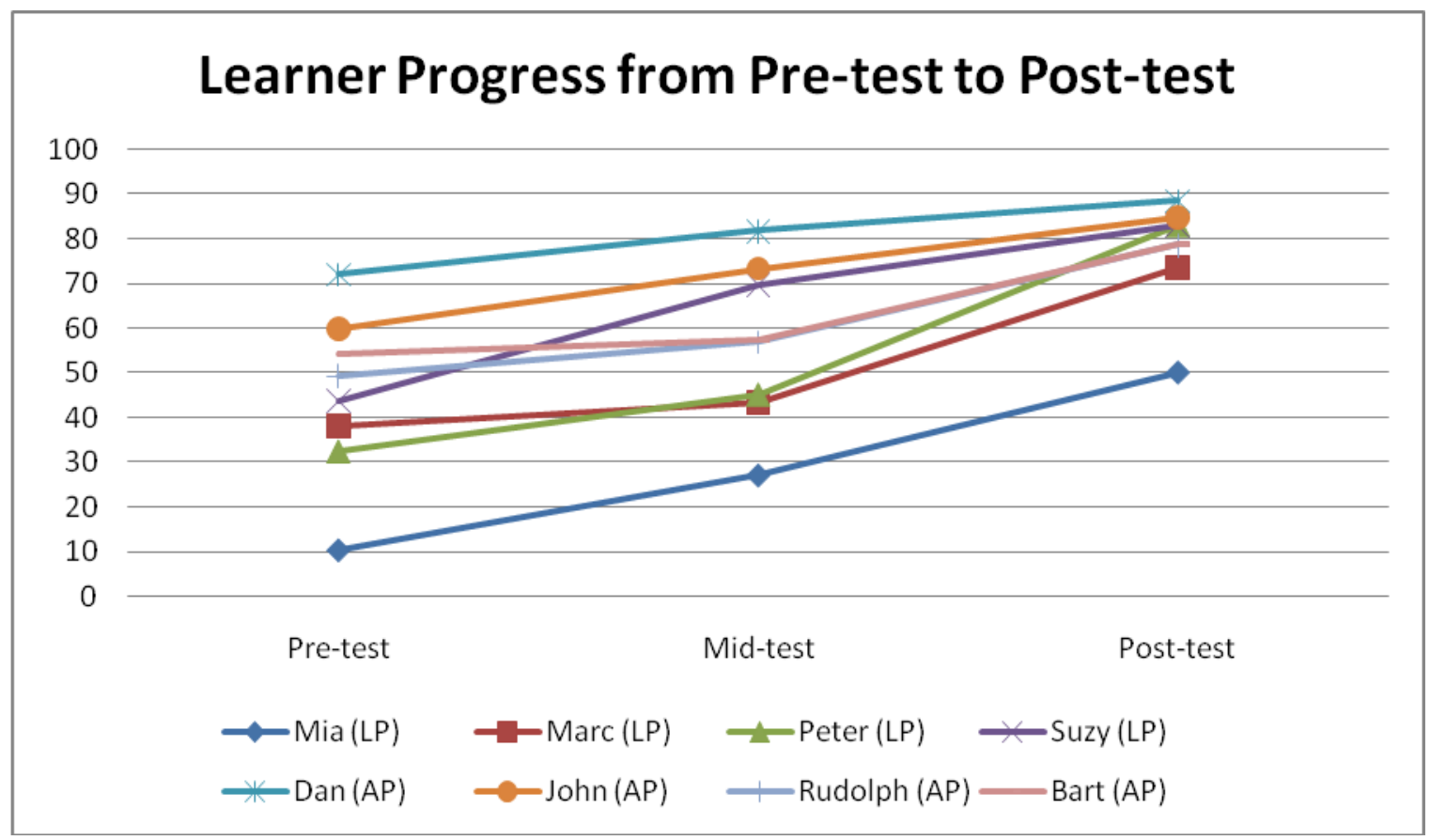

Figure 1: Learner Progress from Pre-test to Post-test

As hypothesised, all learners' average test scores increased from the pre- to the post-test (in Figure 1). Peter and Mia both started at a much lower level than Marc and Suzy in the lowprogress group and achieved a steep incline towards the post-test (Peter improving by 50\%; Suzy by 39\%) whereas John and Bart, who did not participate in the research intervention, displayed a gradual increase towards the post-test (John by $25 \%$; Bart by $24 \%$ ). The cluster of Dan, John, Rudolph and Bart represents what the class average would be for this group of Grade ones. Mia and Marc did not reach this average grade level, but a sharp increase in scores proved their progress (Mia by $40 \%$; Marc by 32\%). Therefore all four learners in the target group, Mia, Marc, Peter and Suzy, increased their test scores from the pre-test to the post-test with the knowledge that they gained from the research-based lessons and also the knowledge each learner gained in the classroom.

These results have further implications. Consider, for example, the sharp increase in the scores of four of the learners after the mid-test, which confirms Clay's (2001: 46) finding that progress in literacy is often not equal or gradual, but may occur in rapid spurts of growth over short time intervals. This highlights the opposition between additive models which view reading as simple accumulation of items that can be captured in test scores and cognitive processing models which view reading progress as changes in the complexity of the processing systems over short time intervals (Clay, 2001: 48).

A second implication of these results is that an individual learner's rate of progress can be accelerated (Swart, 2011: 24). Every learner in the target group's average at the pre-test was lower than all the control group learners. However, by the time the post-test was conducted, some of the low-progress learners had caught up with the average-progress learners, as indicated by the cluster at the post-test. This means that the low-progress learners were able to accelerate their learning over the same period of time during which the learning of average-progress learners maintained a gradual rate of increase. This is illustrated in the percentage increase of the low-progress learners compared to the average-progress learners. The low-progress learners achieved an increase of $35 \%$ and above from pre-test to post-test, 
with Peter achieving an increase of 51\%. The average-progress learners achieved an increase of $29 \%$ and below from pre-test to post-test, with Rudolph achieving the highest increase of $29 \%$. Therefore, the individualised contingent literacy programme was successful in increasing the average assessment scores of each learner. Research-based literacy lessons were thus shown to be successful in the context of my research.

The third implication concerns the improvement of even the lowest performing learners. Although Mia remained well below the average-progress group by post-test, she made a great gain in her own average scores during the research, i.e. $10.3 \%$ at pre-test, $27 \%$ at mid-test and $50 \%$ at post-test. This shows that any learner is ready to learn and improve their literacy skills, given the opportunity and proper research-informed teaching.

\section{STATISTICAL DATA}

Because of the small sample size, it was expected that all the assessments would test nonsignificant (Kidd, 2010). However, after three months of individualised instruction, the target group made significant progress in the Letter Identification and Hearing and Recording Sounds in Words tests (see Addendum A). Both these tests are important indicators of later reading abilities (Adams, 1990; Wray, 1994). These results also show that letters do not have to be taught in isolation; the holistic stance that I took in the intervention enabled the learners to gain an extensive network of knowledge about letter-sound correspondences. In addition, children's ability to control sound-to-letter links is an important strategy for constructing letter knowledge and for authentic writing. Clay (2002: 35) found that children at risk in reading could produce sounds for letters, but found it difficult to hear sound sequences in the words they spoke. Consequently, they were unable to monitor their letter-sound knowledge. Because they were taught that letters make sounds, they did not realise that they could relate these to the sounds in their own speech streams.

From Figure 1 it is evident that the learners in the target group progressed in the other areas as well. Thus, I hypothesise that, with longer exposure to individualised literacy instruction, the other tests would also yield significant results. This is corroborated by the qualitative analyses of the data, which are discussed next.

\section{INTERPRETATION OF QUALITATIVE DATA}

Purcell-Gates (2009: 1) makes the point that instructional programmes derived solely from statistical research have no change of solving the problems in education because of the fact that the significance of individual diversity in sequences of learning is averaged out. For this reason, the qualitative data in the pilot study were used to gain insight into the literacy behaviours of the target group. The qualitative analysis in particular revealed improvements in the target group's (a) use of strategies for comprehending text; (b) development of vocabulary, syntax and narrative structure; and (c) emotional responses to reading and writing tasks.

\section{STRATEGIES FOR COMPREHENDING TEXT}

Based on my knowledge of the target group's classroom contexts (Swart, 2011: 61), I anticipated low assessment scores and minimal use of strategic reading behaviours at the onset of the intervention. The learners' running records showed that they all (i.e. both low- 
and average-progress groups) used the same initial strategies for solving unknown words. These were (a) guessing words from initial letters, e.g. Ben/Because (the learner's substation appears before the dash, followed by the actual text); and (b) sounding out, e.g. j-e-r-s-e$y /$ jersey. This represented the phonic-based approach and it was the only way by which the learners could solve a word that they wanted to read. This, therefore, was the starting point from which the research-based literacy lessons in the intervention programme commenced.

Clay (1991) argues that successful readers develop strategic cognitive competencies that failing readers do not seem to build. Helping the children in the target group to become successful readers by teaching them cognitive strategies for literacy learning therefore was a priority in my intervention. The isolated items teaching approach in the classroom created isolated knowledge stores in learners' minds without links between different kinds of knowledge (Lyons, 2003). The learners first needed to be taught to search for and link essential information from text and connect this to their personal experiences (Clay, 1991; Pinnell \& Fountas, 2001).

Meanings lie in stretches of text, not in isolated words (Clay, 1991: 313). However, the learners in the target group were over-committed to the idea that reading was word recognition and sounding out. Consequently, they neglected to use the syntactic and semantic cues in the text or to monitor their understanding. This was evident from the absence of selfcorrection (monitoring behaviour) at points of error in the learners' running records; the lack of rereading behaviours as well as inappropriate substitutions (e.g. he likes/lives in an $\mathrm{ig} /$ igloo loo/he). Overall, at initial testing, the learners in my study exhibited similar reading behaviours to those described in Buly and Valencia's (2002) study, namely, they relied on a phonics approach, but they struggled with comprehension. They had an over-simplified view of what they really needed to learn and to activate in their brains, in order to read and write. From their findings, Buly and Valencia (2002) concluded that policies which mandate the use of phonics instruction for low-progress readers miss the needs of the majority of these learners.

The learners in the target group also resorted to 'picture-reading' by inventing text based on the pictures, as illustrated in the extract below:

\begin{tabular}{|l|l|}
\hline Text & $\begin{array}{l}\text { Learner's 'reading' (an invention based on } \\
\text { the pictures) }\end{array}$ \\
\hline $\begin{array}{l}\text { In goes the brush } \\
\text { Off come the shoes }\end{array}$ & $\begin{array}{l}\text { Here's the brush but the doggy was scared } \\
\text { Time to get ready for bed } \\
\text { The doggy is funny }\end{array}$ \\
\hline
\end{tabular}

Figure 2: Learners' invented 'picture reading'

The implication of this, for me, was to help the learners attend to the print in text as the main source of information, but to demonstrate that pictures could assist, rather than direct, their reading of a text. When used correctly, print-picture verification assists learners in engaging their "neural processes in "dealing" with visual language on one hand and nonverbal objects on the other' (Paivio, 2008: 102).

Through persistent practice, inappropriate reading behaviours can become resistant to change (Dermitzki et al., 2008: 486). It was apparent from my research results that the learners needed assistance from me (and, by implication, from their classroom teacher) to 'unlearn' 
incorrect links and behaviours and 'relearn' appropriate strategies and behaviours before ineffective behaviours became a habit (Clay, 2002: 15, 27). I also aimed to expand the learners' repertoire of problem-solving strategies for unlocking the meaning of texts. These critical literacy processing behaviours can only be captured through qualitative data.

By the end of the intervention, the qualitative analysis of the learners' running records showed that all four learners in the target group were able to employ comprehension strategies in a 'fluid cycle' of predicting-monitoring-self-correcting, provided they were allowed to read texts appropriate to their current level of understanding (Block \& Duffy, 2008: 29). This varied from learner to learner. Mia, for example, could activate this comprehension cycle on level-1 texts, whereas Suzy could comprehend level-5 texts. Essentially, this meant that the learners had progressed from merely decoding text to comprehending text. Mia enjoyed linking emergent-level texts with personal experiences and predicting what could happen next (Block \& Duffy, 2008; Martin \& Hydén 2006; Pinnell, 2001)). Marc and Peter changed their intonation to a whisper where the text described a mouse's careful movements with an owl lurking in the background, thereby showing that they understood what they were reading. In short, the target group learners were busy establishing the cognitive processes that successful readers have learned to use (Clay, 1991:4).

Fountas and Pinnell (2007: 223) point out that 'the cognitive actions readers employ while processing print are essentially the same across levels'. Readers need to learn to apply them to more demanding levels of text. This means that teachers should not teach strategies sequentially, grade by grade, but could rather teach the entire comprehension cycle at each grade level (Block \& Duffy, 2008: 29). Because the good use of strategies in the early grades sustains further learning when reading more complex texts (DeFord et al., 1991: 79, 86; Clay, 2002: 22, 26; Block \& Duffy, 2008: 26-29), each of the low-progress learners were developing a self-extending system that will enable them to learn other subjects.

\section{DEVELOPMENT OF VOCABULARY, SYNTAX AND NARRATIVE STRUCTURE}

The qualitative analysis of the learners' written work indicated that the emphasis on authentic writing had increased the amount of writing the target group did. At pre-test, the learners' low writing vocabulary scores (score range: $5 \%$ - 40\%) indicated that they were unable to use their isolated letter knowledge to produce words or sentences. At post-test the increase in these scores $(28 \%-92 \%)$ indicated that were they were building a store of familiar words that they could spell correctly and use to communicate their ideas.

At initial testing, their low scores in the Hearing and Recording Sounds in Words test (score range: $11 \%$ - 46\%) lent support to Clay's (2001) finding that at-risk readers are frequently unable to relate letters to the phonemes in their speech. Mia, for example, wrote random letter strings for words (e.g. aeol/cat). The gains they made in being able to hear and record sounds in words by the end of the intervention (score range: $51 \%-89 \%$ ), showed that they were able to links sounds in words to their own speech and attach meaning to them.

The qualitative data in the writing vocabulary task also provided evidence that all the learners were developing a number of different strategies for solving and understanding words, such as analogy (make, take, fake); use of name charts to derive new words (Shane shake); knowledge of word categories (we/me, he/dog/cat). Two of the learners were also incorporating narrative and syntactic structures from the books they had read in their written 
work. For example, Suzy, created her own story, 'The bird party', based on a book called 'Party Time'. Her imaginative, written version contained vocabulary and morphological markers (inviting, asked, party, animals) as well as speech marks and syntactic structures ('Yes', said the animals.) similar to those in the 'Party Time'.

The learners' syntax and vocabulary improvement was due to a number of factors, namely the exposure to whole texts; the influence of the researcher-teacher as a demonstrator and model; and the use of good language structures during book discussions and writing exercises (Calkins, Hartman \& White, 2005: 4; Clay, 1991: 70; Weaver, 1994: 336). The learners' language progress can assist them in the social collaborations in the classroom, such as group work. In classroom lessons where learners are required to do group work, each learner can promote his individual learning by observation of how other learners deploy their literacy strategies and behaviours (Weaver, 1994: 334). Thus, good language use is not only important for general conversations, but also for the extraction of valuable information in social situations.

\section{EMOTIONAL RESPONSES TO READING AND WRITING TASKS}

The following comments are taken from my observational notes of individual learners during the early stages of the intervention: 'very nervous, rocks back and forth'; 'unsure, whispers answers to questions'; 'writes in a soft, shaky hand'; 'when struggles to read-becomes scared to try and cowers away'. They reveal the learners' fear of failure and confirm Lyon's (2003) concern that more attention should be given to the emotional origins of learning.

However, as the intervention progressed, the learners' literacy achievements set a motivational cycle in motion. Each learner's improved assessment scores and positive interactions with literacy reflected a growing mastery of literacy challenges. In turn, they developed positive self-concepts through their mastery of literacy challenges, which motivated further learning and resulted in higher expectations of themselves (Lyons, 2003: 188-185). To conclude, the learners' positive emotional orientations and self-concepts were foundational to their success and ensured continued engagement in the literacy learning process (Dahl \& Freppon, 1998).

In summary, the data of my study reflected similar patterns to studies conducted by Clay, (1991: 224) and Nathanson (2008: 148), thereby contributing to 'deliberate knowledge building' in the field of reading acquisition (Delport \& De Vos, 2005: 54-55). At initial testing the learners displayed the following patterns of behaviour: When reading, they lacked the metacognitive strategies to know whether their attempts were correct or not. They did not make sufficient use of syntactic and semantic structures during reading and were over dependent on 'sounding out', memory and illustrations. The exit data illustrated a shift to more controlled, thoughtful reading of texts. Their limited use of strategies increased over a short time span. For example: the learners were able to use prior knowledge to predict upcoming text; detect and self-correct errors; use several cues simultaneously; and maintain fluency. The changes in the learners' literacy behaviours, the shift in their focus of attention to texts and their attainment of strategies support the view that learning to read develops by reading, and learning to write develops by writing. 


\section{RECOMMENDATIONS}

First, the findings stress the importance of further evidence-based research on the effect of individualised intervention programmes for learners who struggle to read and write. Such studies could provide insights into central issues, such as the kinds of instructional interactions that could lead the way to closing the SES-related reading achievement gap (Purcell-Gates, 2009). In South Africa there is an urgent need for research which provides teachers with moment-by-moment learner data that can help them design instruction for the diversity of learners in their classrooms.

Second, from the data gathered in the pilot study it is evident that there is a range of reading abilities in each grade, as well as large gaps in achievement between the lowest achievers and average readers (see Figure 1: Mia and Dan) This calls into question instruction that is based on a prescriptive 'one approach fits all' reading curriculum. It underscores Vygotsky's concept of providing learners with instruction at the cutting edge of their current abilities. It also highlights the need for expert instruction that can help the child make the transition from 'other-assistance' to 'self-assistance' which is critical to independent learning (Lyons, 2003: 48).

Third, there is much disagreement within the literature based on early literacy on whether items-based or more holistic, meaning-based approaches provide the most suitable starting point for teaching reading acquisition. To settle this debate, Clay (2005) suggests that educators and researchers should use observations of children's early reading and writing behaviours as the main source of knowledge about how children develop these competencies. The qualitative data in my study endorse the value of this suggestion. Based on initial testing and my observations of the target learners' responses to literacy tasks during contact sessions, my main task became guiding them beyond decoding to increasing their repertoire of problem-solving strategies on continuous texts. Observational studies conducted internationally (Weaver, 1998; Clay, 2005; Block \& Duffy, 2008) and nationally (Flanagan, 1995; Bloch, 2006; Nathanson, 2008) suggest that some children learn poor habits of responding in phonics-driven programmes that can limit their progress. While most educators agree that children who are learning to read need letter-sound knowledge, the quantitative data in my pilot study indicates that there are better ways of teaching this knowledge than relying on prescriptive, sequenced phonics programmes.

Finally, Lyons (2003) urges educators and researchers to pay more attention to the emotional origins of learning. There is a need for more research that links practice to the theory-base on brain functioning and cognitive processing. Again, the qualitative data in my study showed that, at initial testing, the children in the target group were emotionally insecure. As they gained competence in a safe space where instruction focused on each child's learning needs, their confidence and motivation to engage in reading and writing grew. In South Africa, emotional engagement in learning is particularly critical, because children who disengage from reading instruction in the early years are more likely to drop out of school.

\section{CONCLUSION}

This article advocates early individual instruction for learners who have difficulty with literacy learning. Similarly, in South Africa the 'every child can read' campaign implies that schooling needs to make special provision for at-risk children. Clay (2005: 14) observes that 
we cannot justify providing all children with the same kind of teaching, - 'not when learning is an essential foundation to subsequent success in education'.

It is unrealistic to expect teachers in mainstream classrooms to observe and deliver finelytuned instruction to individuals. Supplementary literacy interventions can relieve teachers of some of the stress of trying to teach large classes of diverse learners, while simultaneously helping individuals who are not making average progress. However, in South Africa, there is mounting evidence that 'old-style' instruction may contribute to some learners' lack of progress (Bloch, 2006, Nathanson, 2008; Van Staden, 2010; Swart, 2011). Without the benefit and guidance of a national research-base, many South African teachers will continue holding on to oversimplified notions of learning, such as, reading is 'sounding out', writing is 'filling in worksheets' and 'some children can't learn'.

\section{REFERENCES}

ADAMS, M. 1990. Beginning to read: Thinking and learning about print. Massachusetts: MIT Press.

BLOCH, C. 2006. Theory and strategy of early literacy in contemporary Africa with special reference to South Africa. Occasional papers 25. Rondebosch: PRAESA.

BLOCK, CC \& GG DUFFY. 2008. Research on teaching comprehension. In Block, CC \& SR Parris (eds), Comprehension instruction research-based best practices. New York: The Guilford Press.

BLOCK, CC \& SR PARRIS. 2008. Using neuroscience to inform reading comprehension instruction. In Block, CC \& SR Parris (eds), Comprehension instruction research-based best practices. New York: The Guilford Press.

BOEKHORST, AK \& JJ BRITZ. 2004. Information literacy at school level: A comparative study between the Netherlands and South Africa. SA Journal Libs \& Info Sci, 70(2):6371.

BULY, M.R., \& VALENCIA, S.W. 2002. Below the bar: Profiles of students who fail state reading assessments. Educational Evaluation and Policy Analysis, 24(3):219 - 239.

CAINE, RN. 2008. How neuroscience informs our teaching of elementary students. In Block, CC SR \& Parris (eds), Comprehension instruction research-based best practices. New York: The Guilford Press.

CALKINS, L. 2001. The art of teaching reading. New York: Longman.

CALKINS, L, A HARTMAN \& Z WHITE. 2005. One to one: The art of conferring with young writers. Portsmouth: Heinemann.

CAZDEN, CB \& MM CLAY. 1992. A Vygotskian interpretation of Reading Recovery. In Cazden, CB (ed). Whole language plus: Essays on literature in the United States and New Zealand. Columbia: Teacher's College Press.

CLAY, M. 1975. What did I write? Portsmouth, NH: Heinemann.

CLAY, M. 1991. Becoming literate: The construction of inner control. Auckland: Heinemann. 
CLAY, M. 1993. Reading Recovery: A guidebook for teachers in training. Auckland: Heinemann.

CLAY, M. 2001. Change over time in children's literacy development. Auckland: Heinemann.

CLAY, M. 2002. An observation survey of early literacy achievement. Second Edition. Portsmouth: Heinemann.

CLAY, M. 2005. Literacy lessons designed for individuals. Part one. Auckland: Heinemann.

DAHL, K \& P FREPPON. 1998. A comparison of inner-city children's interpretations of reading and writing instruction in the early grades in skills based and whole language classrooms. In Weaver, C (ed), Reconsidering a balanced approach to reading. Urbana, Illinois: National Council of TeachersDEFORD, D. 1991. Using reading and writing to support the reader. In Deford, D, C Lyons \& G Pinnell (eds), Bridges to literacy: Learning from reading recovery. Portsmouth: Heinemann. 77-96).

DEFORD, D, CA LYONS \& GS PINNELL. 1991. Bridges to literacy: Learning from reading recovery. Portsmouth: Heinemann.

DELPORT, C. \& DE VOS, A. 2005. Professional research and profession practice. In De Vos, A., Strydom, H., Fouche, C. \& Delport, C. (Eds.), Research at grass roots for the social sciences and human service professsion (3rd edition). Pretoria: Van Schaik (pp.44-55).

DERMITZAKI, I, G AMDREOU \& V PARASKEVA. 2008. High and low reading comprehension achiever's strategic behaviors and their relation to performance in a reading comprehension situation. Reading Psychology, 29:471-492.

DODGE, A. 2009. Heuristics and NCLB standardized tests: A convenient lie. Paper presented at the Department of Education Policy Studies, 1 October 2010, Stellenbosch University.

DORN, LJ, C FRENCH \& T JONES, T. 1998. Apprenticeship in literacy transitions across reading and writing. United States: Stenhouse.

DRYDEN, G \& J VOS. 1994. The learning revolution. London: Accelerated Learning Systems.

FLANAGAN, W. 1995. Reading and writing in junior classes. Cape Town: Maskew MillerLongman.

FLEISCH, B. 2008. Primary education in crisis. Why South African schoolchildren underachieve in reading and mathematics. Cape Town: Juta.

FOUNTAS, IC \& GS PINNELL. 2007. The continuum of literacy learning, grades K-8: Behaviors and understandings to notice, teach and support. Portsmouth: Heinemann.

GERSTEN, R \& J DIMINO. 2006. RTI (Response to Intervention): Rethinking special education for students with reading difficulties (yet again). Reading Research Quarterly, 41(1):99-107.

GOLEMAN, D. 1995. Emotional intelligence: Why it can matter more than IQ. New York: Bantam Books.

GOPNIK, A, MELTZOFF, A.N. \& KUHL, P.K. 1999. The scientist in the crib: What early learning tells us about the mind. New York: Harper Collins Publications. 
GRANT, D. 2009. Media Release: Western Cape's literacy and numeracy challenges [Online]. Available: http://www.wced.wcape.gov.za [2009, December 8].

HORNSBY, D. 2000. A closer look at guided reading. Armadale: Eleanor Curtain.

INTERNATIONAL ASSOCIATION FOR THE EVALUATION OF EDUCATIONAL ACHIEVEMENT, 2008. PIRLS technical report 2006 [Online]. Available: http://www.iea.nl/fileadmin/user_upload/graphics/Publications/p06_technical_report.pd f. [2010, October 10].

JUSTICE, LM. 2006. Evidence-based practice, response to intervention, and the prevention of reading difficulties. Language, Speech, and Hearing in Schools, 37:284-297.

KIDD, M. 2010. Correspondence. June - October, Stellenbosch.

LEEDY, PD. 1993. Practical research planning and design. 5th edition. New York: MacMillan.

LYONS, CA. 2001. The role of emotion in memory and comprehension. In Pinnell, GS \& PL Scharer (eds), Extending our reach: Teaching for comprehension and reading, Grades $K-2$. Columbus: Ohio State University Printing Services.

LYONS, CA. 2003. Teaching struggling readers: How to use brain-based research to maximize learning. Portsmouth: Heinemann.

MARTIN, R \& G HYDÉN. 2006. Step Beyond. Brooklyn Park: Era.

McCARRIER, A. 2001. Teaching for phrasing and fluency: Connections to comprehension. In Pinnell, GS \& PL Scharer (eds), Extending our reach: Teaching for comprehension and reading, Grades $K-2$. Columbus: Ohio State University Printing Services.

MAYKUT, P \& R MOREHOUSE. 1994. Beginning qualitative research, a philosophic and practical guide. London: The Falmer Press. 126-149.

McENEANY, JE, MK LOSE \& RM SCHWARTZ. 2006. A transactional perspective on reading difficulties and response to intervention. Reading Research Quarterly. 41(1):117-128.

MUJIS, D \& D REYNOLDS. 2003. The effectiveness of use of learning support assistants in improving the mathematics achievement of low achieving pupils in primary school. Educational Research, 45(3):219-230.

NATHANSON, RR. 2008. A school-based, balanced approach to early reading instruction for English additional language learners in grades one to four. Unpublished doctoral dissertation. Stellenbosch: University of Stellenbosch.

O’NEIL, J. 1996. On emotional intelligence: A conversation with Daniel Goleman. Educational Leadership, September:6-11.

PAIVIO, A. 2008. Looking at reading comprehension through the lens of neuroscience. In Block, CC \& SR Parris (eds), Comprehension instruction research-based best practices. New York: The Guilford Press.

PAUL, JL \& K MARFO. 2001. Preparation of educational researchers in philosophical foundations of inquiry. Review of Educational Research, 71(4):525-547.

PINNELL, GS. 2001. What does it mean to comprehend a text? In Pinnell, GS \& PL Scharer (eds), Extending our reach: Teaching for comprehension and reading, Grades $K-2$. Columbus: Ohio State University Printing Services. 
PINNELL, GS \& IC FOUNTAS. 2001. From primary to intermediate grades: How do children change as readers? In Pinnell, GS \& PL Scharer (eds), Extending our reach: Teaching for comprehension and reading, Grades $K-2$. Columbus: Ohio State University Printing Services.

PINNELL, GS \& IC FOUNTAS. 2006. Profile: Marie M Clay: Demonstrating that the world can be different. Language Arts, 83(4):364-370.

PINNELL, GS \& IC FOUNTAS. 2009. When readers struggle: Teaching that works. Portsmouth: Heinemann

PINNELL, GS, MD FRIED \& RM ESTICE. 1991. Bridges to literacy learning from reading recovery. Portsmouth: Heinemann.

PURCELL-GATES, V. 2006. The role of qualitative and ethnographic research in educational policy [Online]. Available: www.readingonline.org/articles/purcellgates/index.html [2009, July16].

RUMELHART, D \& J McCLELLAND. 1986. Parallel distributed processing. Vol. 1: Foundations. Cambridge, MA: MIT Press.

SINGLETON Jr., RA, BC STRAITS \& MM STRAITS. 1993. Approaches to social research. $2^{\text {nd }}$ edition. Oxford: Oxford University Press.

SWART, M. 2011. Adapting instruction to meet the individual needs of foundation phase readers and writers. Unpublished Master's dissertation. Stellenbosch University.

VAN STADEN, A. 2010. Enhancing educational performance: Relating the experiences of postgraduate support teaching students involved in a community service project. The Journal of Education, 49:65-89.

VYGOTSKY, L. 1978. Mind in society. Cole, M, V John-Steiner, S Scribner \& E Souberman (eds). Cambridge: Harvard University Press

WESTERN CAPE EDUCATION DEPARTMENT. 2005. Five-year strategic and performance plan 2005/06 to 2009/10. WCED:Cape Town.

WEAVER, C. 1994. Reading process and practice from socio-psycholinguistics to whole language. 2nd edition. Portsmouth: Heinemann.

WRAY, D. 1994. Language and awareness. London: Hodder \& Stoughton.

\section{BIOGRAPHICAL NOTE}

Renee Nathanson is a lecturer in the Department of Curriculum studies at Stellenbosch University. Her research interests include reading comprehension, early literacy intervention and professional development for literacy teachers.

Marika Swart completed Master of Education studies in early literacy: An individualised literacy intervention for low progress readers and writers in the foundation phase. E-mail address: rrn@sun.ac.za 


\section{ADDENDUM A - RESULTS OF LETTER IDENTIFICATION AND HEARING AND RECORDING SOUNDS IN WORD TESTS}

Table 1: ANOVA table for Assessment 1: Letter Identification Task

\begin{tabular}{|l|l|l|}
\hline Effect & F-statistic & p-value \\
\hline Time & $\mathrm{F}(2,12)=14.1$ & $<0.01$ \\
\hline Group & $\mathrm{F}(1,6)=24.04$ & $<0.01$ \\
\hline Group*Time & $\mathrm{F}(2,12)=6.82$ & 0.01 \\
\hline
\end{tabular}

Table 1 represents the ANOVA results for the Letter Identification Task that required the learners' identification of individual letters at pre-, mid- and post-test. The interaction was significant, and therefore only the interaction figure is analysed.

Table 2: Fisher Post Hoc (Time*Group): Letter Identification Task

\begin{tabular}{|l|l|l|l|l|l|}
\hline Time & \multicolumn{1}{|c|}{ Group } & $\begin{array}{c}\text { Assessment 1 } \\
\text { Mean }\end{array}$ & $\begin{array}{c}\text { Assessment 1 } \\
\text { Standard } \\
\text { Error }\end{array}$ & $\begin{array}{c}\text { Assessment 1 } \\
\mathbf{- 9 5 . 0 0 \%}\end{array}$ & $\begin{array}{c}\text { Assessment 1 } \\
\mathbf{+ 9 5 . 0 0 \%}\end{array}$ \\
\hline 1 & Low Progress & 47.50 & 5.39 & 35.76 & 59.24 \\
\hline 1 & $\begin{array}{l}\text { Average } \\
\text { Progress }\end{array}$ & 87.50 & 5.39 & 75.76 & 99.25 \\
\hline 2 & Low Progress & 54.75 & 5.39 & 43.01 & 66.49 \\
\hline 3 & $\begin{array}{l}\text { Average } \\
\text { Progress }\end{array}$ & 92.00 & 5.39 & 80.26 & 103.74 \\
\hline 3 & $\begin{array}{l}\text { Low Progress } \\
\text { Progress }\end{array}$ & 80.25 & 5.39 & 68.51 & 91.99 \\
\hline
\end{tabular}

Table 2 indicates that the low-progress group's time 1 confidence interval does not overlap with the average group's time 1 confidence interval. The same can be read from time 2 . This suggests that, because the low-progress learners were not taught letters directly, they first had to grow accustomed to the researcher's different approach to teaching letter identification. Time three indicates a statistical overlap which shows that the low-progress learners were able to improve their scores in the Letter Identification assessment to meet those of the average-progress learners. The improvement achieved by the low-progress learners indicated that the research approach was successful. 


\section{Assessment 2. Hearing and Recording Sounds in Words}

Table 3: ANOVA table for Assessment 2: Hearing and Recording Sounds in Words

\begin{tabular}{|l|l|l|}
\hline Effect & F-statistic & p-value \\
\hline Time & $\mathrm{F}(2,12)=31.35$ & $<0.01$ \\
\hline Group & $\mathrm{F}(1,6)=5.43$ & 0.06 \\
\hline Group*Time & $\mathrm{F}(2,12)=8.65$ & $<0.01$ \\
\hline
\end{tabular}

Table 3 represents the ANOVA results for the Hearing and Recording Sounds in Words Task that required the learners to identify individual sounds and sound sequences in words, and record these letters, at pre-, mid- and post-test. The interaction was significant, and therefore only the interaction figure is analysed.

Table 4: Fisher Post Hoc (Time*Group): Hearing and Recording Sounds in Words

\begin{tabular}{|l|l|l|l|l|l|}
\hline Time & Group & $\begin{array}{c}\text { Assessment 2 } \\
\text { Mean }\end{array}$ & $\begin{array}{c}\text { Assessment 2 } \\
\text { Standard } \\
\text { Error }\end{array}$ & $\begin{array}{c}\text { Assessment 2 } \\
\mathbf{- 9 5 . 0 0 \%}\end{array}$ & $\begin{array}{c}\text { Assessment 2 } \\
\mathbf{+ 9 5 . 0 0 \%}\end{array}$ \\
\hline 1 & Low Progress & 28.50 & 8.73 & 9.48 & 47.52 \\
\hline 1 & $\begin{array}{l}\text { Average } \\
\text { Progress }\end{array}$ & 72.75 & 8.73 & 53.73 & 91.77 \\
\hline 2 & $\begin{array}{l}\text { Low Progress } \\
\text { Progress }\end{array}$ & 43.00 & 8.73 & 23.98 & 62.02 \\
\hline 3 & Low Progress & 77.50 & 8.73 & 49.98 & 88.02 \\
\hline 3 & $\begin{array}{l}\text { Average } \\
\text { Progress }\end{array}$ & 86.50 & 8.73 & 67.48 & 105.52 \\
\hline
\end{tabular}

Table 4 indicates that the low-progress group has a strong increase tendency in average, although the average-progress group also displays an increase. The average-progress group's increase is not as prominent as that of the low-progress group, considering that the low-progress group's first test time 1 was much lower than the average group, and ended on the same level by test time 3 . This trend implies a more significant result if the sample group had been bigger. 